\title{
Review of environmental factors and juvenile idiopathic arthritis
}

This article was published in the following Dove Press journal:

Open Access Rheumatology: Research and Reviews

\author{
Daniel B Horton (1D ${ }^{1-3}$ \\ Susan Shenoi ${ }^{4}{ }^{4}$ \\ 'Department of Pediatrics, Rutgers \\ Robert Wood Johnson Medical School, \\ New Brunswick, NJ, USA; ${ }^{2}$ Rutgers \\ Center for Pharmacoepidemiology and \\ Treatment Science, Institute for Health, \\ Health Care Policy and Aging Research, \\ New Brunswick, NJ, USA; ${ }^{3}$ Department \\ of Biostatistics and Epidemiology, Rutgers \\ School of Public Health, Piscataway, NJ, \\ USA; ${ }^{4}$ Department of Pediatrics, Division \\ of Pediatric Rheumatology, Seattle \\ Children's Hospital and Research Center \\ and University of Washington, Seattle, \\ WA, USA
}

\begin{abstract}
Juvenile idiopathic arthritis is a common rheumatic disease that presents as chronic childhood arthritis. JIA is considered a multifactorial disease that may result from diverse genetic and environmental risk factors. A minority of the population-attributable risk of JIA is estimated to be due to familial factors. Thus, non-genetic or environmental factors likely account for a majority of the risk of developing JIA. Yet, while substantial data have linked environmental factors to the development of rheumatoid arthritis, similar evidence regarding JIA is sparse. This narrative review provides updates on recent literature about environmental factors that might influence the risk of developing JIA, including studies about potentially beneficial and harmful influences as well as factors with unclear effects.
\end{abstract}

Keywords: environmental exposure, risk factors, juvenile arthritis, antibiotics, breast feeding, cesarean section

\section{Introduction}

Juvenile idiopathic arthritis (JIA) represents an array of biologically distinct, incompletely understood forms of chronic inflammatory arthritis beginning in childhood. JIA has been classified into six or seven categories based on associated clinical and laboratory features. ${ }^{1,2}$ Recent approaches incorporating biologic information from cytokine profiles and genetics have led to alternative proposed classifications of JIA. $^{3,4}$ JIA is thought to originate from a complex interplay of non-Mendelian genetics $^{5}$ and environmental influences leading to chronic inflammation of joints and other tissues. ${ }^{6}$ Familial epidemiologic studies and genome-wide association studies have produced estimates of the contribution of genetic factors to JIA ranging from $13 \%$ to $25 \%{ }^{7-9}$ While these numbers could rise with advancements in genetics, ${ }^{10}$ physicians and families alike grapple with questions about the sizable missing heritability of JIA specifically with the potentially outsized role of the environment on JIA pathogenesis.

Mechanistically, environmental influences may trigger JIA via several different mechanisms, including epigenetic changes, imbalance of microbiota, and direct modulation of the immune system. In keeping with Dr. Barkers hypothesis that postulates adult diseases might have their origins in utero, ${ }^{11}$ we also discuss links between postulated in utero exposures including maternal smoking and others with JIA. Details about these potential mechanisms, including relevant references, have been reviewed elsewhere. ${ }^{12-14}$ In this narrative review, we discuss recent advances in our understanding of environmental factors that might relate to JIA pathogenesis and highlight some limitations of research on environmental influences on disease.
Correspondence: Susan Shenoi Division of Rheumatology, Seattle Children's Hospital, Mailstop: MA.7.I I0, 4800 Sand Point Way NE, Seattle, WA 98105 , USA

Tel + I 2069872000

Fax + I 2069875060

Email susan.shenoi@seattlechildrens.org 


\section{Environmental factors and JIA} Potentially protective factors

\section{Breast-feeding}

Breastfeeding has been associated with numerous health benefits, including possible prevention of immune-mediated diseases. ${ }^{15}$ Breastmilk contains natural prebiotics and probiotics and has been linked to favorable changes in infants' gut microbiota (e.g., increased commensal Bifidobacteria, reduced potentially pathogenic commensals [pathobionts], ${ }^{16-20}$ alteration in DNA methylation profiles, ${ }^{21}$ and other immunologically protective factors (e.g., soluble IgA, IgG, IL-10, TGFb, defensins). ${ }^{22}$

Multiple prior studies have examined the connection between breastfeeding and JIA, reporting disparate findings (Table 1). The first publication on this topic, a casecontrol study, reported a potentially protective effect, with a lower frequency of breastfeeding in JIA (37\%) than in unaffected peers $(60 \%) .{ }^{23}$ Cases were less likely to breastfeed for $>3$ months compared to controls ( $15 \%$ vs $34 \%$ ). This study, however, had several methodologic limitations, including a small sample size with questionable generalizability, unmeasured confounding, and the potential for selection bias and recall bias (Table 1). Subsequent casecontrol studies did not show a significantly decreased risk of JIA among breastfed children; ${ }^{24-28}$ one among them reported an increased risk of oligoarticular JIA in breastfed children. ${ }^{28}$ While all but one of these studies were larger, they, too, had similar limitations (Table 1). A recent study from southeast Sweden reported that breastfeeding could delay or prevent JIA in some children. ${ }^{29}$ Unlike all other previous research on this topic, this study was performed within a population-based birth inception cohort that prospectively collected information about early feeding practices, well before JIA was diagnosed. Children who developed JIA were significantly less likely to breastfeed for more than 4-6 months after adjustment for multiple factors, including parental education, family history, early life infections, and smoke exposure. As a negative control, there was no evident association between early life feeding and transient forms of arthritis, lending specificity to the correspondence between breastfeeding and JIA. A multicenter study of a UK-based JIA cohort suggested that early breastfeeding could modify JIA phenotype and severity. ${ }^{30}$ In this cohort, breastfed children were more likely to be diagnosed at younger ages and have better physician global, parent global, pain, and physical function (Childhood Health Assessment Questionnaire, CHAQ) scores, with longer durations of breastfeeding corresponding to progressively lower scores. However, group differences in global, pain, and functional scores may have been related to unmeasured confounders; parent global scores differed between groups more markedly than physician scores, and there were no apparent differences between groups in active joint counts or inflammatory markers.

\section{Siblings}

The hygiene hypothesis ${ }^{31}$ posits that early exposures to infections (e.g., from older siblings) and non-pathogenic microbiota help protect children against subsequent immune dysfunction and autoimmunity. Children with older siblings tend to have higher level of Bifidobacteria commensals early in life, and number of siblings correlates with increased bacterial diversity and richness, which are generally accepted markers of microbial health. ${ }^{16,32,33}$ Microchimerism - gestational acquisition of cells or DNA from a mother or sibling - represents another mechanism by which JIA risk may be different among children with siblings. ${ }^{34}$

Research on the potential effects of siblings in JIA has been variable in size, quality, and findings. One early Danish study with population-based controls and some adjustment for socioeconomic status (SES) suggested that children with JIA were less likely to have household siblings, without relation to sibling age (Table 1). ${ }^{35}$ Two subsequent population-based case-control studies showed no such relationship: a study of JIA and birth order based on 333 cases in the western US (with minimal confounder adjustment) ${ }^{36}$ and a study of JIA and number of older siblings based on 3334 hospitalized cases in Sweden. ${ }^{37}$ Neither study specifically examined the role of siblings in the household, unlike the subsequent Childhood Arthritis Risk Factor Identification Study (CLARITY) from southeast Australia. ${ }^{25,38}$ This study collected detailed environmental information from 302 cases with JIA and community- and hospital-based controls. The authors reported a decreased risk of JIA among children with household siblings, with some analyses showing additionally diminished risk in those with more siblings (i.e., an apparent dose response). Results were discordant between hospitalbased and community-based controls regarding birth order and the dose-response with sibling number for unclear reasons; the sample of community-based controls, while theoretically more valid than hospital-based controls, was also smaller and limited by imprecise estimates in several analyses. Age of JIA diagnosis and closeness in age to siblings did not modify the results. Another recent population-based case-control study used clinic records linked to birth 


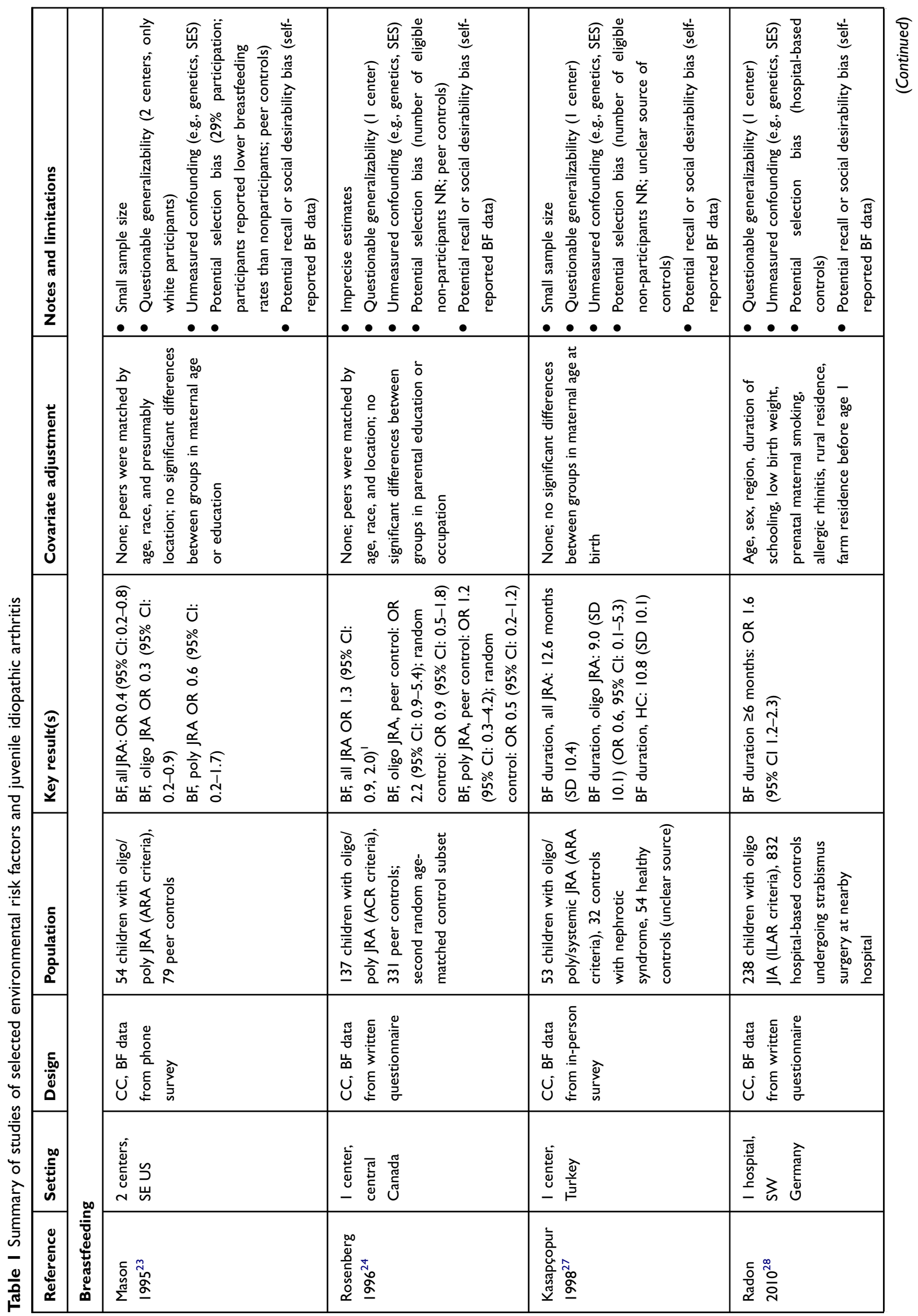




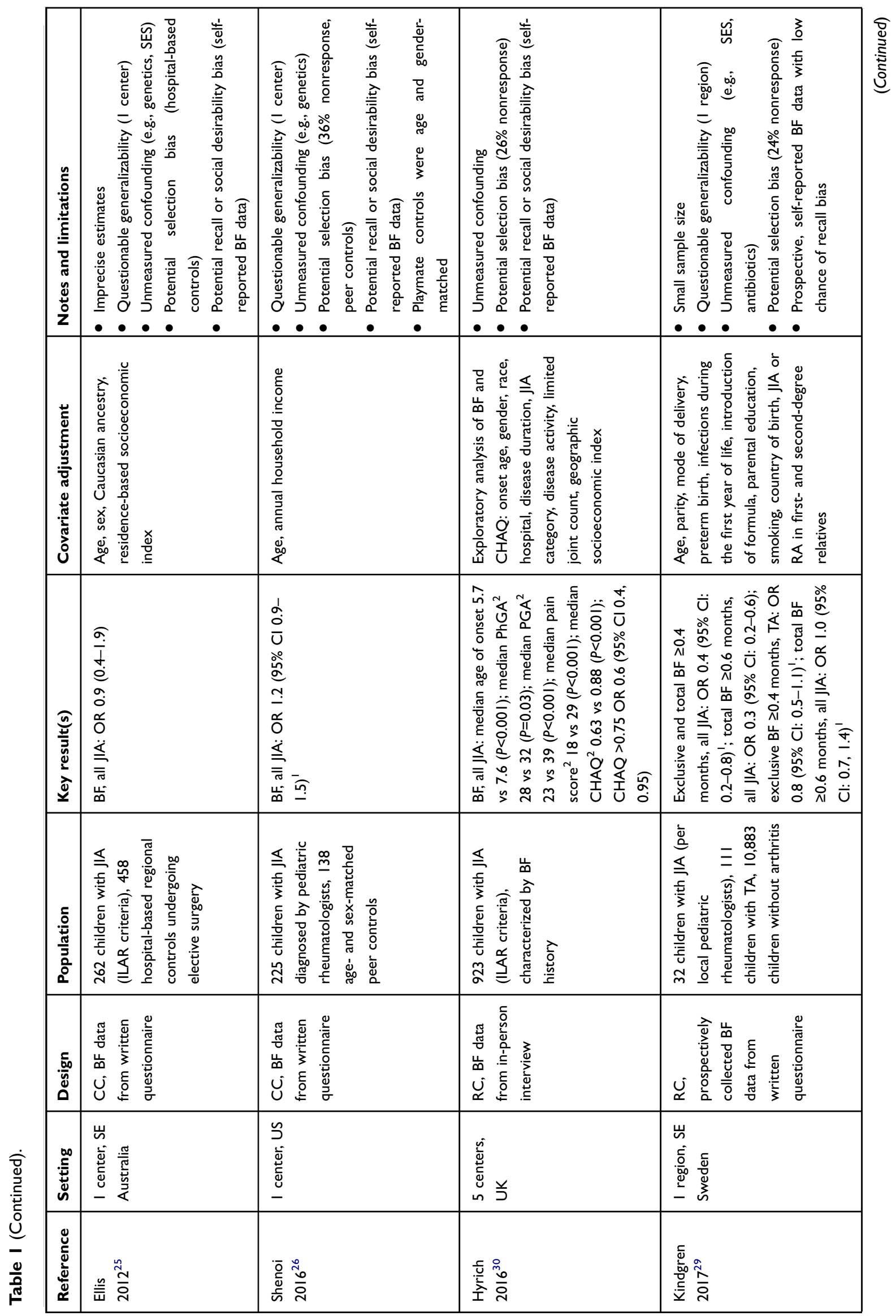




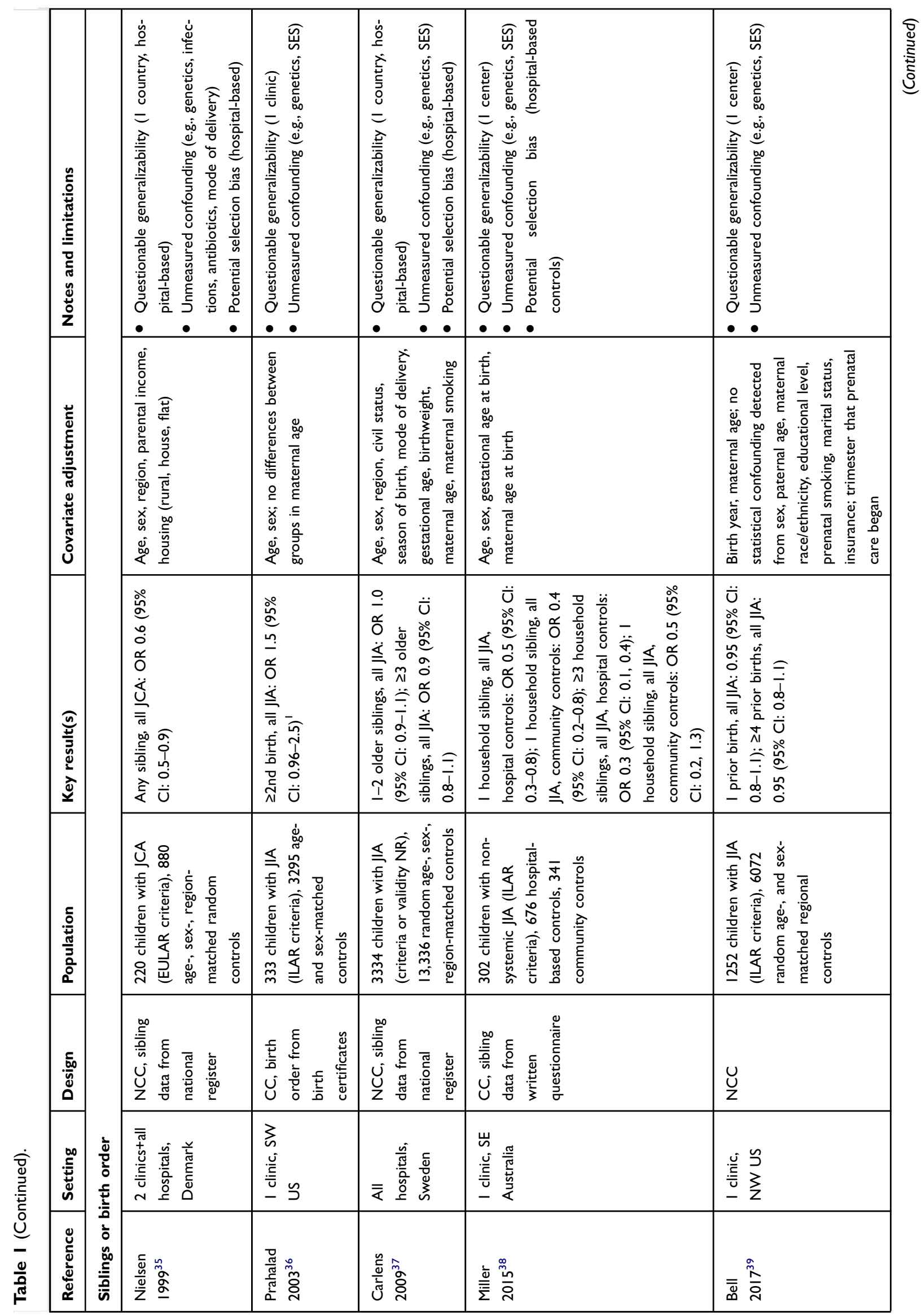




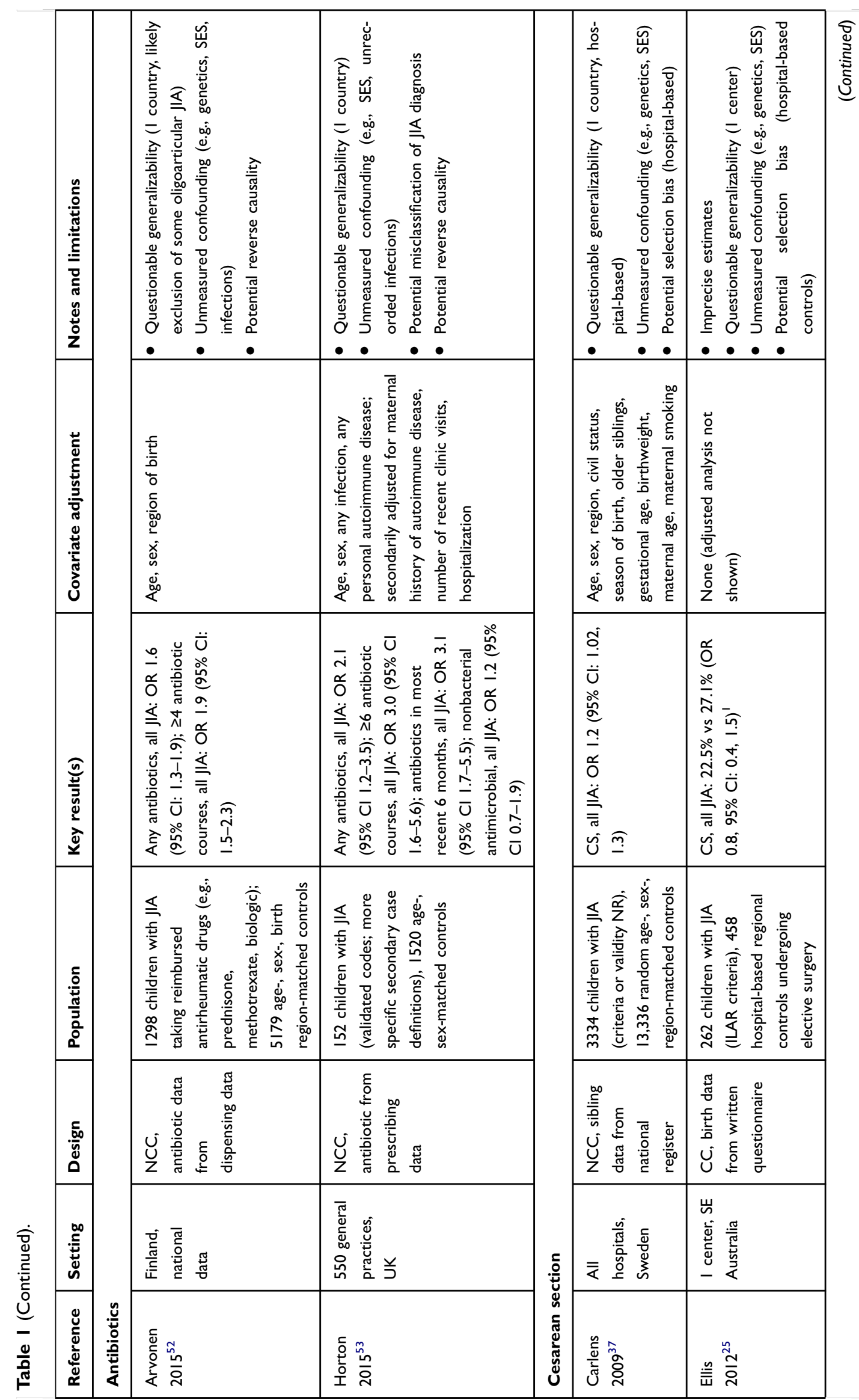




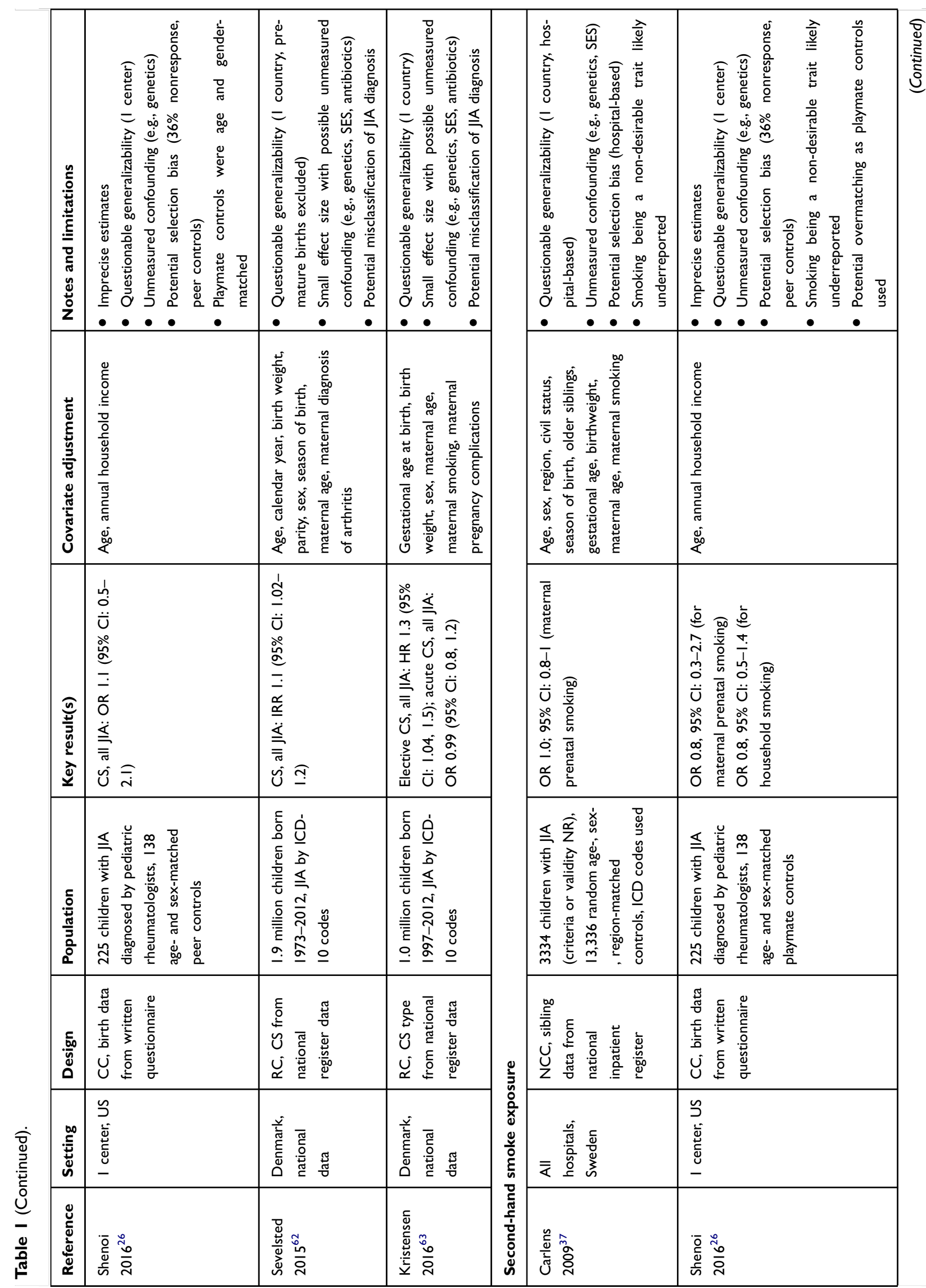




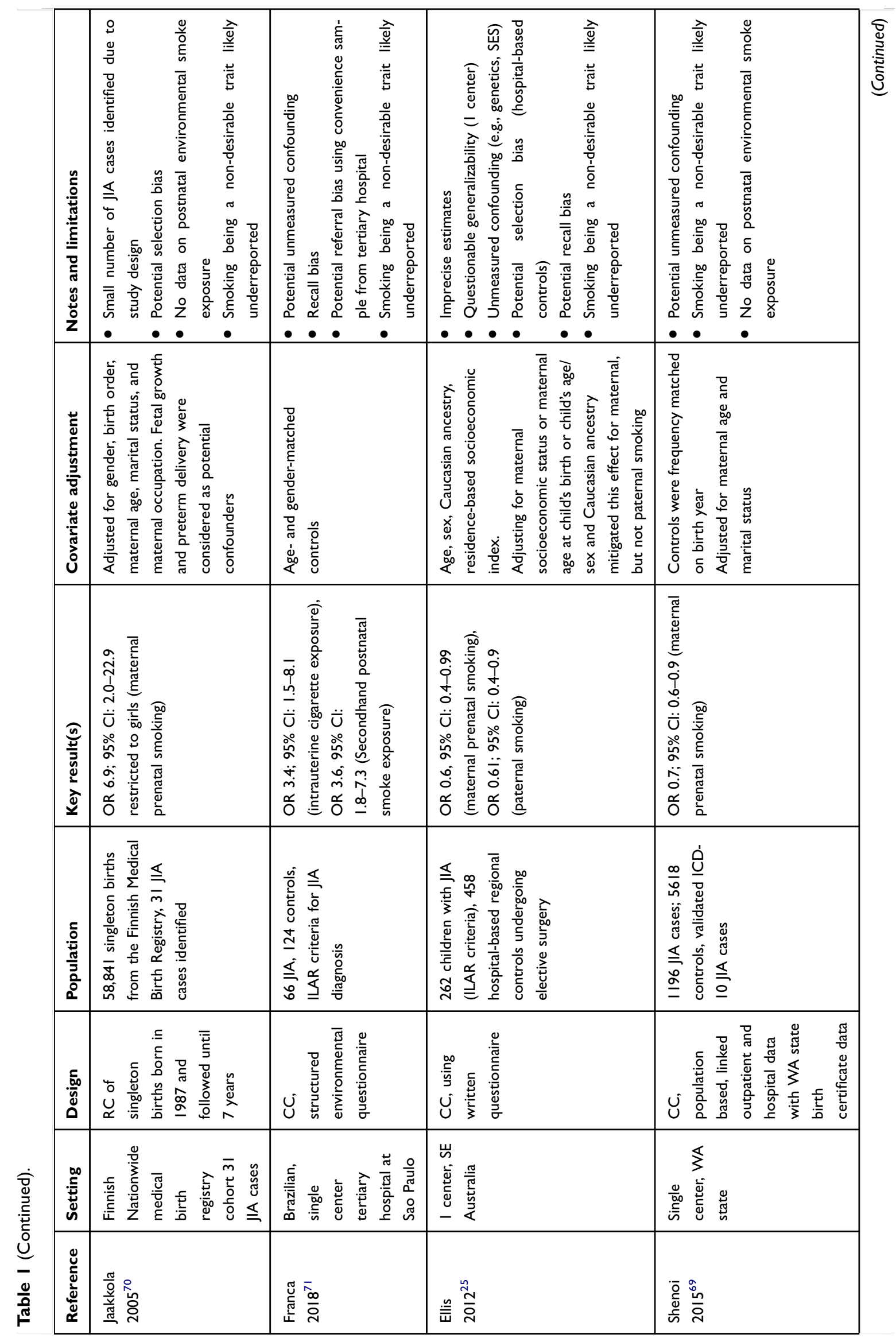




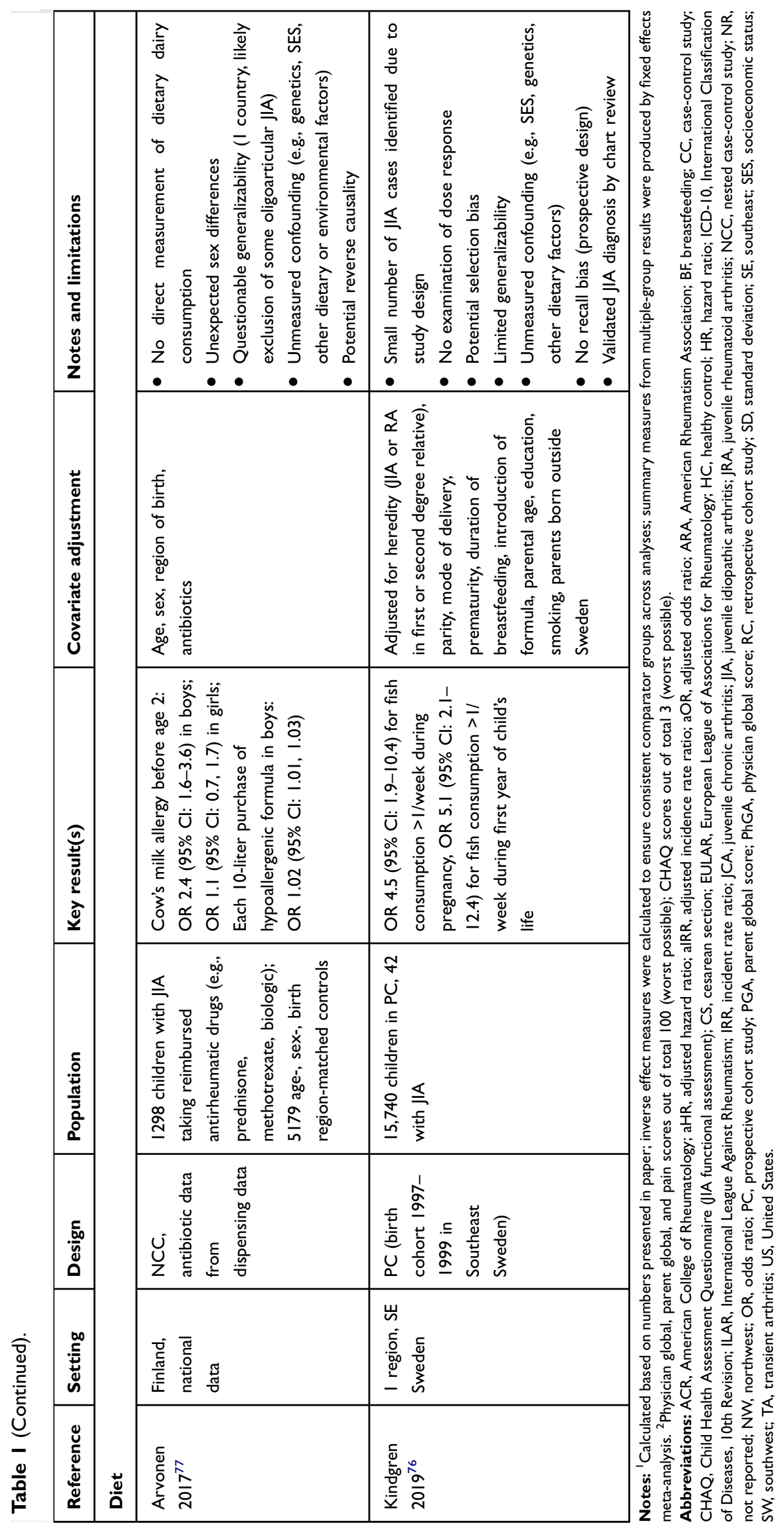


certificates from the northwest US to examine the relationship between JIA and birth order. ${ }^{39}$ Based on 1234 cases from a single large clinic, this study found an inverse relationship between number of prior births and risk of JIA. Similar trends were observed for multiple JIA categories, although sample size limited the statistical power of subgroup analyses.

In summary, research on the role of breastfeeding and household siblings as potential modifiers of JIA risk has yielded contradictory and inconclusive findings from observational studies of variable quality. More recent studies suggest the possibility that breastfeeding and having multiple siblings may protect from the development of JIA. However, strong conclusions about these effects are limited particularly by concerns about residual confounding from SES and genetic factors. More definitive answers, especially regarding the effects of breastfeeding, may require other designs (e.g., sibling-controlled cohort studies, large randomized trials).

\section{Potentially harmful factors Infectious agents}

Infection has long been purported to contribute to JIA pathogenesis or trigger JIA flares. Prior reviews have discussed the mixed evidence about bacterial and viral infections as potential triggers of JIA. ${ }^{6,40}$ Some studies have noted an association between exposure to enteric bacteria (gut pathogens and pathobionts) and enthesitis-related arthritis in developing nations where gastrointestinal infections are more common. ${ }^{41-43}$ However, the patho-etiologic role of infections in causing JIA, and the mediating role of genetic factors (e.g., HLA-B27), remain unclear. ${ }^{44}$

\section{Antibiotic exposure}

Antibiotics can cause profound short-term declines in bacterial diversity and changes in bacterial composition and function. ${ }^{45,46}$ Typically, microbiota recover within 1-2 months, but some antibiotic-exposed individuals have altered microbial composition for months or years, particularly after repeat antibiotic exposures. ${ }^{47,48}$ Young children exposed to antibiotics can have altered composition and decreased diversity measured up to two years, changes that correspond to types of antibiotics received. ${ }^{49}$ Some children with newly diagnosed JIA have higher levels of Bacteroidetes, ${ }^{50,51}$ a change also seen after antibiotic exposure. ${ }^{49}$

Two population-based studies have shown that children diagnosed with JIA are more likely to receive prior antibiotics, and more courses of antibiotics, than age- and sex- matched controls. ${ }^{52,53}$ One study from Finland showed that children taking antirheumatic drugs for JIA (e.g., oral prednisone, methotrexate, or biologic) were more likely to receive any antibiotics earlier in life, with stronger effects among children with multiple prior courses (Table 1). ${ }^{52}$ Though uncommonly used, clindamycin exposure was associated with particularly high rates of JIA in a dose-dependent fashion (any use, OR 6.6, 95\% CI 3.7-11.7; 2-3 courses, OR $16.0,95 \%$ CI $4.5-56.7)$. While this study did not adjust for confounding from infections, another nested case-control study from the UK similarly found that cases with JIA were more likely exposed to antibiotics after adjusting for both infections and prior diagnosis of another autoimmune disease (Table 1). ${ }^{53}$ This association was also dose-dependent as well as time-dependent: the strongest risk of JIA came within one year of antibiotic exposure (OR $\sim 3$ ), with no appreciable association $>2$ years after last exposure. These findings were corroborated through secondary definitions of exposure and outcome and robust to multiple sensitivity analyses. One sensitivity analysis showed that antibiotic-treated and presumably viral upper respiratory tract infections were associated with JIA, but untreated URIs were not, further implicating antibiotics as a potential trigger.

Nonetheless, both studies were still observational and could not rule out all sources of bias, notably, residual confounding from unmeasured factors (e.g., genetics) and protopathic bias or reverse causality, whereby underlying immune dysfunction ultimately manifesting in JIA predisposed children to more serious infections before diagnosis.

\section{Cesarean (C) section delivery}

The path newborns take leaving the womb may have important immunologic implications. Compared to vaginally delivered infants, those born by cesarean section tend to have lower levels of circulating cytokines and leukocyte responsiveness. ${ }^{54-56}$ Children born via elective $\mathrm{C}$-section may also have long-lasting immune deficits compared to children born after labor. ${ }^{57} \mathrm{C}$-section deliveries also correspond to early decreases in microbial diversity and lower proportions of beneficial Bifidobacteria, particularly elective $\mathrm{C}$-sections without laboring or even abbreviated exposure to the birth canal. ${ }^{17,58,59}$ Early microbiota disruptions due to mode of delivery might mediate subsequent differences in infants' immune responsiveness. ${ }^{60}$ Broadly speaking, C-section deliveries could predispose children to subsequent immunologic dysfunction and disorders. ${ }^{61}$

Several studies have examined the relationship between mode of delivery and JIA. Two case-control 
studies, each with 200-300 cases, were unable to show a significant association between mode of delivery and JIA but were underpowered to do so (Table1) ${ }^{25,26}$ However, three large population-based studies from Scandinavia-a hospital-based case-control study from Sweden and two cohort studies from Denmark - showed small but significantly increased risks of JIA among children born by Csection. ${ }^{37,62,63}$ The Swedish study and one Danish study both produced effect estimates of similar magnitude: OR 1.15 (95\% CI 1.02-1.30) and IRR 1.10 (95\% CI 1.021.18) (Table 1). The second Danish study suggested that this association changed based on type of $\mathrm{C}$-section: elective C-section was associated with increased risk of JIA (HR 1.25, 95\% CI 1.04-1.51) but acute C-section was not (HR 0.99, 95\% CI 0.81-1.20). These observations are compatible with the hypothesis that unlabored $\mathrm{C}$-sections may slightly increase the risk of JIA due to changes in post-partum microbiota and immune response. However, such mechanistic explanations are speculative. All of these studies were limited by incomplete adjustment for confounding.

\section{Unclear associations Seasonality}

Clustering of JIA incidence in certain seasons might favor etiologies that peak similarly during certain seasons, such as infections. A study of 28 children with systemic JIA from Kansas, USA, showed peaks in certain months, i.e., spring (May) and autumn (September), that might suggest enteroviral etiology. ${ }^{64}$ In contrast, a retrospective study within Canadian pediatric rheumatology centers from 1980 to 1992 did not reveal seasonal clustering of new cases with systemic JIA except for increases in JIA incidence in the Prairie region in spring (May) and autumn (September-November); notably, this timing did not coincide with local viral outbreaks. ${ }^{65}$ Another multicenter retrospective study of 59 patients with systemic JIA in Israel did not demonstrate any obvious season of onset of disease. ${ }^{66}$ However, another Israeli study of 558 children with multiple types of JIA noted a pattern in patients' months of birth when compared to the general population, with peaks in births from late fall and winter (NovemberMarch) and a nadir in summer, particularly for enthesitisrelated arthritis. ${ }^{67}$ The working hypothesis for season of birth as a risk factor in JIA is that an environmental agent (such as infection or sun exposure) during that particular season may trigger an autoimmune process in the fetal or perinatal period.

\section{Second-hand smoke exposure}

Personal smoking is the most consistent environmental risk factor linked to the development of seropositive rheumatoid arthritis in adults. ${ }^{68}$ However, the relationship of JIA incidence to second-hand smoke exposure either in utero or in childhood is less clear. Studies from different populations have yielded different results, ranging from null effects to markedly positive associations to modest inverse associations ${ }^{25,26,37,69-71}$ (Table 1). Given their many limitations, including unmeasured confounding and potential recall bias, it is difficult to draw strong conclusions from these studies about the role of second-hand smoke exposure on JIA risk.

\section{Pollutants (air and other occupational exposures)}

Inhaled air pollutants such as carbon monoxide, sulfur dioxide, ozone, particulate air matter, or nitrates are thought to cause oxidative stress or inflammation leading to systemic autoimmune disease. A case-crossover study from urban regions of Utah, USA, analyzed the association between short-term air conditions and JIA onset, with a focus on fine particulate matter (aerodynamic diameter $\leq 2.5 \mu \mathrm{m}$, or $\mathrm{PM}_{2.5}$ ). Among 338 children diagnosed with JIA, elevated $\mathrm{PM}_{2.5}$ concentrations in the preceding 14 days were associated with an increased risk of JIA onset in children younger than 5.5 years (RR 1.6, 95\% CI: 1-2.5), with stronger effects seen in boys and children with systemic JIA. ${ }^{72}$ In a separate study focused on systemic JIA, the same group found an increased relative risk of systemic JIA within 14 days following $\mathrm{PM}_{2.5}$ exposure in children under 5.5 years (RR 1.75, 95\% CI 0.85-3.62), although this association did not meet traditional levels of statistical significance. ${ }^{73}$ These studies were limited by their consideration only of short-term pollutant exposures and lack of adjustment for other time-varying confounders (e.g., infections).

A Brazilian study conducted over 7 years (2000-2007) studied the relationships between daily concentrations of inhaled particulate matter $\left(\mathrm{PM}_{10}\right)$, sulfur dioxide $\left(\mathrm{SO}_{2}\right)$, nitrogen dioxide $\left(\mathrm{NO}_{2}\right)$, ozone $\left(\mathrm{O}_{3}\right)$, and carbon monoxide (CO) and hospital admissions for several pediatric rheumatic diseases, including JIA, systemic lupus, dermatomyositis, systemic scleroderma, ankylosing spondylitis, and vasculitis. This study reported an association between $\mathrm{SO}_{2}$ and pediatric rheumatic disease admissions following a 2-week lag. ${ }^{74}$ They did not report JIA admissions and pollutant exposure and it would seem that JIA patients are less often admitted to the hospital thus limiting this study. Another Brazilian casecontrol study of 66 JIA and 124 age- and sex-matched 
healthy controls residing in Sao Paulo found increased risk of maternal occupational exposure during pregnancy to inhalable particulate pollutants and/or volatile vapor with OR 13.7 (95\% CI: 4.4-42.3) using a structured questionnaire. ${ }^{71}$ This study was limited by potential bias from unmeasured confounding and potential referral bias from use of convenience sample from a tertiary center and recall bias.

\section{Perinatal risk factors}

The study by Carlens et al reported borderline associations between JIA and the following perinatal characteristics: postdates delivery ( $>42$ weeks gestation), OR 1.3 (95\% CI: $1-1.3)$; and Apgar scores $\leq 6$ at 5 mins, OR 0.7 (95\% CI: 0.5-1). No significant associations were found between JIA and other perinatal risk factors, including maternal age, birthweight, multiple births, malformations, birth season, or maternalchild blood group incompatibility. ${ }^{37}$ Similarly, Shenoi et al did not find any association between JIA diagnosis and birth weight or place of delivery. However, children born pre-term were more likely to develop JIA (OR 1.8, 95\% CI: 1.2-2.7). ${ }^{26}$ The limitations of these studies have been discussed previously (see Table 1).

\section{Dietary factors}

Families of children with JIA often perceive that diet plays an important role in modulation of disease activity. ${ }^{75}$ This raises the question of whether dietary factors could contribute to pathogenesis. A Swedish-population-based cohort study found that fish consumption ( $>1$ time per week) during pregnancy or in the first year of a child's life was associated with a markedly increased risk of developing JIA. Additionally, the authors reported higher levels of aluminum, mercury, cadmium, and lithium in the cord blood of children with JIA compared to controls, supporting the hypothesis that the association is mediated by exposure to heavy metals in fish (Table 1). ${ }^{76}$ This study did not, however, report the presence of a clear dose-response or the influence of confounding from other dietary or environmental factors. A population-based study from Finland showed that boys diagnosed with a cow's milk allergy and exposed to hypoallergenic formula before age 2 were more likely to develop JIA (Table 1). ${ }^{77}$ This association was not present in girls, raising questions about the biologic mechanism and relevance of this unexpected sex difference. Of note, this study did not directly examine the effect of early-life consumption of dairy products and had similar limitations to the prior Finnish study on antibiotics and JIA, including unmeasured confounding (Table 1). ${ }^{52}$

\section{Sun exposure and vitamin D}

Multiple studies have shown that vitamin D levels are generally low in children diagnosed with JIA and may correspond to disease activity and manifestations, ${ }^{78,79}$ but few studies have explored whether vitamin D plays a role in JIA incidence, none via examination of dietary vitamin D intake. A Danish case-cohort study of 300 matched pairs of oligo and polyarticular JIA did not find any association between vitamin D levels at birth (assessed by neonatal dried blood spots) and subsequent JIA development (OR 1.2; 95\% CI: 0.9-1.6). ${ }^{80}$ Using CLARITY data, a sub-study of 202 Caucasian JIA agematched case-control pairs born in Victoria Australia and matched on birth year and time of recruitment demonstrated that higher cumulative ultraviolet radiation or sun exposure was associated with significantly reduced risk for subsequent JIA development. ${ }^{81}$ They also found that higher the sun exposure during 12 weeks of pregnancy lower the risk for JIA and hypothesized that the mechanism through which sun exposure might influence JIA risk is through active vitamin D circulating levels. Using SNP data from the CLARITY study, Ellis et al also demonstrated that epistasis (gene-gene interaction) between PTPN2 and vitamin D pathway genes might contribute to risk of JIA. ${ }^{82}$

\section{Miscellaneous risk factors}

Other factors have been studied in JIA including

- SES (higher income parents higher risk (RR 1.9) of JIA $)^{35}$

- Residence (urban residence had increased risk RR $2.7,^{35}$ or no risk with area of residence) ${ }^{26}$

- Animal exposure (pet exposure during infancy was not related to oligoarticular JIA (OR 0.79), ${ }^{28}$ or household pet exposure was not associated with JIA ${ }^{26}$ and

- Stressors ${ }^{83}$ (no risk, ${ }^{26}$ or strong association with stressors antedating first clinic visit) ${ }^{84}$

These studies are relatively small and show inconsistent results making it difficult to determine causal nature of associations.

\section{Common limitations of environmental research}

The vast majority of studies investigating environmental links to diseases such as JIA are observational, leading to inevitable questions about whether epidemiologic associations imply causality. Investigators may not measure or account for factors relating independently to an environmental exposure and the 
outcome (for instance, SES, genetic, and other environmental factors), potentially distorting the true associations through confounding. Long latency times between exposures (e.g., prenatal and perinatal factors) and outcomes make confounding more likely. Furthermore, when participants self-report remote environmental exposures, the findings may be impacted by faulty recall (exposure misclassification) and differential recall between cases and controls (recall bias). Selection of proper controls in case-control studies (the most commonly used design cited in this review) is critical to making valid comparisons between groups. Selecting controls by convenience (e.g., hospital-based controls) or in ways that do not represent the same population source as cases can lead to selection bias. Other challenges to interpreting observational studies on environmental exposures may relate to uncertainties about when environmental risks have the most impact on disease development; synergistic effects among multiple exposures or with genetic factors (gene-environment interactions); and use of highly curated cases that limit generalizability to broader populations (e.g., single-center studies). Additional challenges arise in research on JIA, including heterogeneity of disease, evolving and inconsistent disease classification, low disease incidence leading to small sample sizes, and lack of standardized registries.

\section{Conclusion}

Evidence on the role of environmental factors in the development of JIA is slowly expanding, including potential protective influences from breast feeding and household siblings and potential risks from antibiotic exposure and $\mathrm{C}$-section deliveries. Nonetheless, many uncertainties remain about the role of these and other factors in JIA pathogenesis. The role of diet in JIA, while of greater interest to patients and caregivers, remains largely unexplored. More definitive findings about the role of purported and novel yet unidentified environmental factors in JIA pathogenesis will require robust study designs applied to large populations along with mechanistic studies. Such approaches should leverage the tools of systems biology and examine how environmental factors (the "exposome") interact with genomics, epigenomics, and the microbiome other -omics in children who develop or are at risk for JIA. The confirmation of true environmental protective and risk factors for JIA will help inform policies and interventions that could one day help prevent JIA in susceptible children and improve patient outcomes.

\section{Disclosure}

Dr Daniel B Horton reports grants from NIH/NIAMS, during the conduct of the study and grants from BristolMyers Squibb, outside the submitted work. Dr Susan Shenoi reports Shenoi honorarium for Novartis Advisory Board, outside the submitted work. The authors report no other conflicts of interest in this work.

\section{References}

1. Petty RE, Southwood TR, Manners P, et al. International league of associations for rheumatology classification of juvenile idiopathic arthritis: second revision, Edmonton, 2001. J Rheumatol. 2004;31 (2):390-392.

2. Martini A, Ravelli A, Avcin T, et al. Toward new classification criteria for juvenile idiopathic arthritis: first steps, pediatric rheumatology international trials organization international consensus. $J$ Rheumatol. 2019;46(2):190-197. doi:10.3899/jrheum.180168

3. Eng SW, Duong TT, Rosenberg AM, Morris Q, Yeung RS. REACCH OUT and BBOP research consortia. The biologic basis of clinical heterogeneity in juvenile idiopathic arthritis. Arthritis Rheumatol. 2014;66(12):3463-3475. doi:10.1002/art.38875

4. Nigrovic PA, Raychaudhuri S, Thompson SD. Review: genetics and the classification of arthritis in adults and children. Arthritis Rheumatol. 2018;70(1):7-17. doi:10.1002/art.40350

5. Hersh AO, Prahalad S. Genetics of juvenile idiopathic arthritis. Rheum Dis Clin North Am. 2017;43(3):435-448. doi:10.1016/j.rdc.2017.04.007

6. Ellis JA, Munro JE, Ponsonby AL. Possible environmental determinants of juvenile idiopathic arthritis. Rheumatology (Oxford). 2010;49(3):411-425. doi:10.1093/rheumatology/kep383

7. Prahalad S, Zeft AS, Pimentel R, et al. Quantification of the familial contribution to juvenile idiopathic arthritis. Arthritis Rheum. 2010;62 (8):2525-2529. doi:10.1002/art.27516

8. Savolainen A, Saila H, Kotaniemi K, Kaipianen-Seppanen O, Leirisalo-Repo M, Aho K. Magnitude of the genetic component in juvenile idiopathic arthritis. Ann Rheum Dis. 2000;59(12):1001. doi:10.1136/ard.59.12.1001

9. Hinks A, Cobb J, Marion MC, et al. Dense genotyping of immune-related disease regions identifies 14 new susceptibility loci for juvenile idiopathic arthritis. Nat Genet. 2013;45(6):664-669. doi:10.1038/ng.2614

10. Moncrieffe H, Prahalad S, Thompson SD. Genetics of juvenile idiopathic arthritis: new tools bring new approaches. Curr Opin Rheumatol. 2014;26(5):579-584. doi:10.1097/BOR.0000000000000094

11. Barker DJ. The developmental origins of adult disease. J Am Coll Nutr. 2004;23(6Suppl):588S-595S. doi:10.1080/07315724.2004.10719428

12. van Loosdregt J, van Wijk F, Prakken B, Vastert B. Update on research and clinical translation on specific clinical areas from biology to bedside: unpacking the mysteries of juvenile idiopathic arthritis pathogenesis. Best Pract Res Clin Rheumatol. 2017;31(4):460475. doi:10.1016/j.berh.2018.02.003

13. De Filippo C, Di Paola M, Giani T, Tirelli F, Cimaz R. Gut microbiota in children and altered profiles in juvenile idiopathic arthritis. $J$ Autoimmun. 2019;98:1-12. doi:10.1016/j.jaut.2019.01.001

14. Horton DB. Juvenile idiopathic arthritis and the gut microbiome: more clues, more questions. Arthritis Rheumatol. 2019;71(6):842845. doi:10.1002/art.40842

15. Vieira Borba V, Sharif K, Shoenfeld Y. Breastfeeding and autoimmunity: programing health from the beginning. Am J Reprod Immunol. 2018;79(1):Epub 2017 Oct 30. doi:10.1111/aji.12778

16. Penders J, Thijs C, Vink C, et al. Factors influencing the composition of the intestinal microbiota in early infancy. Pediatrics. 2006;118 (2):511-521. doi:10.1542/peds.2005-2824 
17. Azad MB, Konya T, Maughan H, et al. Gut microbiota of healthy Canadian infants: profiles by mode of delivery and infant diet at 4 months. CMAJ. 2013;185(5):385-394. doi:10.1503/cmaj.121189

18. Fan W, Huo G, Li X, et al. Diversity of the intestinal microbiota in different patterns of feeding infants by illumina high-throughput sequencing. World J Microbiol Biotechnol. 2013;29(12):2365-2372. doi:10.1007/s11274-013-1404-3

19. Voreades N, Kozil A, Weir TL. Diet and the development of the human intestinal microbiome. Front Microbiol. 2014;5:494. doi:10.3389/fmicb.2014.00547

20. Bridgman SL, Azad MB, Field CJ, et al. Fecal short-chain fatty acid variations by breastfeeding status in infants at 4 months: differences in relative versus absolute concentrations. Front Nutr. 2017;4:11. doi:10.3389/fnut.2017.00011

21. Hartwig FP, Loret de Mola C, Davies NM, Victora CG, Relton CL, Tost J. Breastfeeding effects on DNA methylation in the offspring: a systematic literature review. PLoS One. 2017;12(3):e173070. doi:10.1371/journal.pone.0173070

22. Hennet T, Borsig L. Breastfed at tiffany's. Trends Biochem Sci. 2016;41(6):508-518. doi:10.1016/j.tibs.2016.02.008

23. Mason T, Rabinovich CE, Fredrickson DD, et al. Breast feeding and the development of juvenile rheumatoid arthritis. $J$ Rheumatol. 1995;22(6):1166-1170.

24. Rosenberg AM. Evaluation of associations between breast feeding and subsequent development of juvenile rheumatoid arthritis. $J$ Rheumatol. 1996;23(6):1080-1082.

25. Ellis JA, Ponsonby AL, Pezic A, et al. CLARITY - childhood arthritis risk factor identification sTudY. Pediatr Rheumatol Online J. 2012;10(1):37-0096-10-37. doi:10.1186/1546-0096-10-24

26. Shenoi S, Shaffer ML, Wallace CA. Environmental risk factors and early-life exposures in juvenile idiopathic arthritis: a case-control study. Arthritis Care Res (Hoboken). 2016;68(8):1186-1194. doi:10.1002/acr.22806

27. Kasapcopur O, Tasdan Y, Apelyan M, et al. Does breast feeding prevent the development of juvenile rheumatoid arthritis? $J$ Rheumatol. 1998;25(11):2286-2287.

28. Radon K, Windstetter D, Poluda D, et al. Exposure to animals and risk of oligoarticular juvenile idiopathic arthritis: a multicenter casecontrol study. BMC Musculoskelet Disord. 2010;11:73-2474-11-73. doi:10.1186/1471-2474-11-73

29. Kindgren E, Fredrikson M, Ludvigsson J. Early feeding and risk of juvenile idiopathic arthritis: a case control study in a prospective birth cohort. Pediatr Rheumatol Online J. 2017;15(1):46-017-0175-z. doi:10.1186/s12969-017-0175-z

30. Hyrich KL, Baildam E, Pickford H, et al. Influence of past breast feeding on pattern and severity of presentation of juvenile idiopathic arthritis. Arch Dis Child. 2016;101(4):348-351. doi:10.1136/archdischild-2014-308117

31. Rook GA. Hygiene hypothesis and autoimmune diseases. Clin Rev Allergy Immunol. 2012;42(1):5-15. doi:10.1007/s12016-011-8285-8

32. Penders J, Gerhold K, Thijs C, et al. New insights into the hygiene hypothesis in allergic diseases: mediation of sibling and birth mode effects by the gut microbiota. Gut Microbes. 2014;5(2):239-244. doi:10.4161/gmic. 27905

33. Laursen MF, Zachariassen G, Bahl MI, et al. Having older siblings is associated with gut microbiota development during early childhood. BMC Microbiol. 2015;15:154-015-0477-6. doi:10.1186/s12866-015-0477-6

34. Nelson JL. The otherness of self: microchimerism in health and disease. Trends Immunol. 2012;33(8):421-427. doi:10.1016/j.it.2012.03.002

35. Nielsen HE, Dorup J, Herlin T, Larsen K, Nielsen S, Pedersen FK. Epidemiology of juvenile chronic arthritis: risk dependent on sibship, parental income, and housing. J Rheumatol. 1999;26(7):1600-1605.

36. Prahalad S, Fraser AM, O'Brien E, Kerber RA, Mineau GP, Bohnsack JF. Lack of association between birth order and juvenile idiopathic arthritis. Arthritis Rheum. 2003;48(10):2989-2990. doi:10.1002/art.11297
37. Carlens C, Jacobsson L, Brandt L, Cnattingius S, Stephansson O, Askling J. Perinatal characteristics, early life infections and later risk of rheumatoid arthritis and juvenile idiopathic arthritis. Ann Rheum Dis. 2009;68(7):1159-1164. doi:10.1136/ard.2008.089342

38. Miller J, Ponsonby AL, Pezic A, et al. Sibling exposure and risk of juvenile idiopathic arthritis. Arthritis Rheumatol. 2015;67(7):19511958. doi:10.1002/art.39129

39. Bell SW, Shenoi S, Nelson JL, Bhatti P, Mueller BA. Juvenile idiopathic arthritis in relation to perinatal and maternal characteristics: a case control study. Pediatr Rheumatol Online J. 2017;15 (1):36-017-0167-z. doi:10.1186/s12969-017-0167-z

40. Rigante D, Bosco A, Esposito S. The etiology of juvenile idiopathic arthritis. Clin Rev Allergy Immunol. 2015;49(2):253-261. doi:10.1007/s12016-014-8460-9

41. Singh YP, Singh AK, Aggarwal A, Misra R. Evidence of cellular immune response to outer membrane protein of salmonella typhimurium in patients with enthesitis-related arthritis subtype of juvenile idiopathic arthritis. J Rheumatol. 2011;38(1):161-166. doi:10.3899/ jrheum. 100542

42. Saxena N, Misra R, Aggarwal A. Is the enthesitis-related arthritis subtype of juvenile idiopathic arthritis a form of chronic reactive arthritis? Rheumatology (Oxford). 2006;45(9):1129-1132. doi:10.1093/rheumatology/kel056

43. Pacheco-Tena C, Alvarado De La Barrera C, Lopez-Vidal Y, et al. Bacterial DNA in synovial fluid cells of patients with juvenile onset spondyloarthropathies. Rheumatology (Oxford). 2001;40(8):920-927. doi:10.1093/rheumatology/40.8.920

44. Rosenbaum JT, Davey MP. Time for a gut check: evidence for the hypothesis that HLA-B27 predisposes to ankylosing spondylitis by altering the microbiome. Arthritis Rheum. 2011;63(11):3195-3198. doi:10.1002/art.30558

45. Dethlefsen L, Huse S, Sogin ML, Relman DA. The pervasive effects of an antibiotic on the human gut microbiota, as revealed by deep 16S rRNA sequencing. PLoS Biol. 2008;6(11):e280. doi:10.1371/ journal.pbio.0060098

46. Perez-Cobas AE, Gosalbes MJ, Friedrichs A, et al. Gut microbiota disturbance during antibiotic therapy: a multi-omic approach. Gut. 2013;62(11):1591-1601. doi:10.1136/gutjnl-2012-303184

47. Jernberg C, Lofmark S, Edlund C, Jansson JK. Long-term ecological impacts of antibiotic administration on the human intestinal microbiota. Isme J. 2007;1(1):56-66. doi:10.1038/ismej.2007.3

48. Dethlefsen L, Relman DA. Incomplete recovery and individualized responses of the human distal gut microbiota to repeated antibiotic perturbation. Proc Natl Acad Sci U S A. 2011;108(Suppl 1):45544561. doi:10.1073/pnas.1000087107

49. Korpela K, Salonen A, Virta LJ, et al. Intestinal microbiome is related to lifetime antibiotic use in finnish pre-school children. Nat Commun. 2016;7:10410. doi:10.1038/ncomms10410

50. Tejesvi MV, Arvonen M, Kangas SM, et al. Faecal microbiome in new-onset juvenile idiopathic arthritis. Eur J Clin Microbiol Infect Dis. 2016;35(3):363-370. doi:10.1007/s10096-015-2548-x

51. Stoll ML, Weiss PF, Weiss JE, et al. Age and fecal microbial strainspecific differences in patients with spondyloarthritis. Arthritis Res Ther. 2018;20(1):14-018-1510-6. doi:10.1186/s13075-018-1510-6

52. Arvonen M, Virta LJ, Pokka T, Kroger L, Vahasalo P. Repeated exposure to antibiotics in infancy: a predisposing factor for juvenile idiopathic arthritis or a sign of this group's greater susceptibility to infections? $J$ Rheumatol. 2015;42(3):521-526. doi:10.3899/jrheum.140348

53. Horton DB, Scott FI, Haynes K, et al. Antibiotic exposure and juvenile idiopathic arthritis: a case-control study. Pediatrics. 2015;136(2):e333-e343. doi:10.1542/peds.2015-0573

54. Yektaei-Karin E, Moshfegh A, Lundahl J, Berggren V, Hansson LO, Marchini $G$. The stress of birth enhances in vitro spontaneous and IL8 -induced neutrophil chemotaxis in the human newborn. Pediatr Allergy Immunol. 2007;18(8):643-651. doi:10.1111/j.1399-3038. 2007.00578.x 
55. Almanzar G, Schonlaub J, Hammerer-Lercher A, Koppelstaetter C, Bernhard D, Prelog M. Influence of the delivery modus on subpopulations and replication of lymphocytes in mothers and newborns. Early Hum Dev. 2015;91(12):663-670. doi:10.1016/j.earlhumdev.2015.09.010

56. Puff R, D'Orlando O, Heninger AK, et al. Compromised immune response in infants at risk for type 1 diabetes born by caesarean section. Clin Immunol. 2015;160(2):282-285. doi:10.1016/j.clim.2015.06.008

57. Martikainen MV, Keski-Nisula L, Jakupovic H, et al. The lack of natural processes of delivery and neonatal intensive care treatment lead to impaired cytokine responses later in life. Am $J$ Reprod Immunol. 2017;77(3). Epub 2017 Jan 3. doi:10.1111/aji.12621

58. Rutayisire E, Huang K, Liu Y, Tao F. The mode of delivery affects the diversity and colonization pattern of the gut microbiota during the first year of infants' life: a systematic review. BMC Gastroenterol. 2016;16(1):86-016-0498-0. doi:10.1186/s12876-016-0498-0

59. Stokholm J, Thorsen J, Chawes BL, et al. Cesarean section changes neonatal gut colonization. J Allergy Clin Immunol. 2016;138(3):881889.e2. doi:10.1016/j.jaci.2016.01.028

60. Wampach L, Heintz-Buschart A, Fritz JV, et al. Birth mode is associated with earliest strain-conferred gut microbiome functions and immunostimulatory potential. Nat Commun. 2018;9(1):5091018-07631-x. doi:10.1038/s41467-018-07631-x

61. Sandall J, Tribe RM, Avery L, et al. Short-term and long-term effects of caesarean section on the health of women and children. Lancet. 2018;392(10155):1349-1357. doi:10.1016/S0140-6736(18)31930-5

62. Sevelsted A, Stokholm J, Bonnelykke K, Bisgaard H. Cesarean section and chronic immune disorders. Pediatrics. 2015;135(1):e92-e98. doi:10.1542/peds.2014-0596

63. Kristensen K, Henriksen L. Cesarean section and disease associated with immune function. J Allergy Clin Immunol. 2016;137(2):587590. doi:10.1016/j.jaci.2015.07.040

64. Lindsley CB. Seasonal variation in systemic onset juvenile rheumatoid arthritis. Arthritis Rheum. 1987;30(7):838-839. doi:10.1002/ art.1780300719

65. Feldman BM, Birdi N, Boone JE, et al. Seasonal onset of systemiconset juvenile rheumatoid arthritis. J Pediatr. 1996;129(4):513-518. doi:10.1016/s0022-3476(96)70115-4

66. Uziel Y, Pomeranz A, Brik R, et al. Seasonal variation in systemic onset juvenile rheumatoid arthritis in Israel. J Rheumatol. 1999;26 (5):1187-1189

67. Berkun Y, Lewy H, Padeh S, Laron Z. Seasonality of birth of patients with juvenile idiopathic arthritis. Clin Exp Rheumatol. 2015;33 (1):122-126.

68. Klareskog L, Padyukov L, Alfredsson L. Smoking as a trigger for inflammatory rheumatic diseases. Curr Opin Rheumatol. 2007;19 (1):49-54. doi:10.1097/BOR.0b013e32801127c8

69. Shenoi S, Bell S, Wallace CA, Mueller BA. Juvenile idiopathic arthritis in relation to maternal prenatal smoking. Arthritis Care Res (Hoboken). 2015;67(5):725-730. doi:10.1002/acr.22471

70. Jaakkola JJ, Gissler M. Maternal smoking in pregnancy as a determinant of rheumatoid arthritis and other inflammatory polyarthropathies during the first 7 years of life. Int J Epidemiol. 2005;34(3):664-671. doi:10.1093/ije/dyi006
71. Franca CMP, Sallum AME, Braga ALF, Strufaldi FL, Silva CAA, Farhat SCL. Risk factors associated with juvenile idiopathic arthritis: exposure to cigarette smoke and air pollution from pregnancy to disease diagnosis. J Rheumatol. 2018;45(2):248-256. doi:10.3899/ jrheum. 161500

72. Zeft AS, Prahalad S, Lefevre S, et al. Juvenile idiopathic arthritis and exposure to fine particulate air pollution. Clin Exp Rheumatol. 2009;27(5):877-884

73. Zeft AS, Prahalad S, Schneider R, et al. Systemic onset juvenile idiopathic arthritis and exposure to fine particulate air pollution. Clin Exp Rheumatol. 2016;34(5):946-952.

74. Vidotto JP, Pereira LA, Braga AL, et al. Atmospheric pollution: influence on hospital admissions in paediatric rheumatic diseases. Lupus. 2012;21(5):526-533. doi:10.1177/0961203312437806

75. Little EM, Grevich S, Huber JL, et al. Parental perception of dietary intervention in juvenile idiopathic arthritis. J Altern Complement Med. 2019;25(6):643-647. doi:10.1089/acm.2018.0407

76. Kindgren E, Guerrero-Bosagna C, Ludvigsson J. Heavy metals in fish and its association with autoimmunity in the development of juvenile idiopathic arthritis: a prospective birth cohort study. Pediatr Rheumatol Online J. 2019;17(1):33-019-0344-3. doi:10.1186/s12969019-0344-3

77. Arvonen M, Virta LJ, Pokka T, Kroger L, Vahasalo P. Cow's milk allergy in infancy and later development of juvenile idiopathic arthritis: a register-based case-control study. Am J Epidemiol. 2017;186 (2):237-244. doi:10.1093/aje/kwx060

78. Finch SL, Rosenberg AM, Vatanparast H. Vitamin D and juvenile idiopathic arthritis. Pediatr Rheumatol Online J. 2018;16(1):34-0180250-0. doi:10.1186/s12969-018-0250-0

79. Sengler C, Zink J, Klotsche J, et al. Vitamin D deficiency is associated with higher disease activity and the risk for uveitis in juvenile idiopathic arthritis - data from a German inception cohort. Arthritis Res Ther. 2018;20(1):276-018-1765-y. doi:10.1186/s13075018-1765-y

80. Thorsen SU, Pipper CB, Alberdi-Saugstrup M, et al. No association between vitamin $\mathrm{D}$ levels around time of birth and later risk of developing oligo- and polyarticular juvenile idiopathic arthritis: a Danish case-cohort study. Scand J Rheumatol. 2017;46(2):104-111. doi:10.1080/03009742.2016.1178325

81. Chiaroni-Clarke RC, Munro JE, Pezic A, et al. Association of increased sun exposure over the life-course with a reduced risk of juvenile idiopathic arthritis. Photochem Photobiol. 2019;95(3):867873. doi:10.1111/php. 13045

82. Ellis JA, Scurrah KJ, Li YR, et al. Epistasis amongst PTPN2 and genes of the vitamin D pathway contributes to risk of juvenile idiopathic arthritis. J Steroid Biochem Mol Biol. 2015;145:113-120. doi:10.1016/j.jsbmb.2014.10.012

83. Herrmann M, Scholmerich J, Straub RH. Stress and rheumatic diseases. Rheum Dis Clin North Am. 2000;26(4):737-63, viii.

84. Neufeld KM, Karunanayake CP, Maenz LY, Rosenberg AM. Stressful life events antedating chronic childhood arthritis. J Rheumatol. 2013;40(10):1756-1765. doi:10.3899/jrheum.121505
Open Access Rheumatology: Research and Reviews

\section{Publish your work in this journal}

Open Access Rheumatology Research and Reviews is an international, peer-reviewed, open access journal publishing original research, reports, editorials, reviews and commentaries on all aspects of clinical and experimental rheumatology in the clinic and laboratory including the following topics: Pathology, pathophysiology of rheumatological diseases; Investigation, treatment and management of rheumatological diseases; Clinical trials and novel pharmacological approaches for the treatment of rheumatological disorders. The manuscript management system is completely online and includes a very quick and fair peer-review system, which is all easy to use. Visit http://www.dovepress.com/testimonials.php to read real quotes from published authors. 